\title{
HEIDEGGER: TÉCNICA E ESQUECIMENTO DO SER
}

\author{
[HEIDEGGER: TECHNIQUE AND FORGETFULNESS OF BEING]
}

\begin{abstract}
Resumo: Trata-se de circunscrever o sentido do fenômeno da técnica no horizonte do pensamento de Heidegger e sua crítica à metafísica clássica. Para tanto, em um primeiro momento apresentamos o fenômeno da técnica no âmbito de sua leitura dessa metafísica em sua essência: o esquecimento do ser. Em um segundo momento, apresentamos, nos limites de nosso texto e de modo mais particular, dois acenos descortinadores da essência do fenômeno em questão. O primeiro no nexo téchne, verdade e liberdade e o segundo no nexo técnica, ciência e metafísica. Para, então, concluir com uma breve chamada de atenção acerca do que podemos guardar como o legado básico do pensamento de Heidegger acerca dessa central questão para nós da era tecnológica atual.
\end{abstract}

Palavras-chave: Heidegger; Esquecimento do ser; Técnica; Verdade; Liberdade
ABSTRACT: It is about circumscribing the meaning of the phenomenon of technique in the horizon of Heidegger's thought and his critique of classical metaphysics. For that, in a first moment we present the phenomenon of the technique in the scope of its reading of this metaphysics in its essence: the forgetfulness of being. In a second step, we present, within the limits of our text and in a more particular way, two indications of the essence of the phenomenon in question. The first in the technical connection, truth and freedom and the second in the technical, science and metaphysical connection. To conclude, then, with a brief reminder of what we can retain as the basic legacy of Heidegger's thought about this central issue for us in the current technological age.

KEYWORDS: Heidegger; Forgetting of being; Technique; Truth; Freedom

\section{INTRODUÇÃo}

$\mathrm{H}$ eidegger parte do fato do humano estar hoje sob o domínio da técnica. Todavia, procura mostrar que esse fenômeno se insere em um mais amplo, qual seja: a história do esquecimento do $\operatorname{ser}^{1}$. E ainda, que essa história sugere que o humano não se coloca por si mesmo no universo tecnicista. Sua condição não é de controlador desse universo, uma vez que sua condição primeira é de acolher a uma espécie de interpelação do próprio ser (CAMPOS, 1984, p. 54); um "apelo do ser" (HEIDEGGER, 2002, p.215), que subjaz às suas figuras enteficadoras ao longo de sua história no pensamento ocidental, sendo a técnica moderna sua figura última e cabal,

* Doutorado em Filosofia pelo Programa Integrado em Filosofia (UFPB-UFPE-UFRN/2010). Professor Adjunto IV do Departamento e do Programa de Pós-Graduação em Filosofia da Universidade Federal do Piauí, UFPI.E-mail: jrbdias@ufpi.edu.br 
aquela que dá acabamento, dá forma final à metafísica clássica, pressuposto para uma "nova manhã" no pensamento: seu retorno ao pensamento do Ser.

A relevância da apresentação, nos termos heideggeriano, da essência da técnica está, basicamente, no fato de ser ela, por um lado, uma referência básica no tratamento da questão, vez que gerou em torno dela uma escola de pensadores da chamada filosofia da técnica, seja na linha de uma crítica, seja na linha de uma continuidade a ele ${ }^{2}$; e, por outro lado, ela ainda continuar alimentando esse debate como referência a que não se pode prescindir.

Daí a devida apresentação, no sentido da fidelidade a essa essência tal como foi e está desenvolvida nos texto de Heidegger, faz-se sempre necessário, posto que dá a devida direção ao debate face a interpretaçõessuperficiais e até distorcidas do que, de fato, foi e é a contribuição heideggeriana. Para tanto, faremos um movimento duplo, cujo propósito é, tão somente, nos pôr a caminho no livre pensar $d o \mathrm{Ser}$.

\section{TÉCHNE, VERDADE E LIBERDADE}

Ao analisar a essência da verdade, Heidegger (1991a; 1989; 1992) detecta esse caráter apelativo do ser. Ele recusa a enunciação como lugar essencial da verdade, isto é, a verdade como conformidade e correção, já que aquilo que torna possível conformidade e correção tem mais direito a ser considerado a essência da verdade, embora essa ideia tradicional da verdade seja seu ponto de partida. A enunciação e a coisa se conformam enquanto a primeira apresenta a segunda, ou seja, "deixa surgir a coisa diante de nós enquanto objeto" (1991a, p. 125).

Desse modo, o que se opõe a nós - a coisa apresentada — deve já cobrir um âmbito aberto, para que se dê ao nosso encontro e, simultaneamente, permanecer em si mesma, manifestando-se em sua própria estabilidade. O importante é notar que a aparição da coisa se dá numa abertura, cuja natureza de ser aberto não lhe é dada pela enunciação. A enunciação não dá abertura, ela se dá numa abertura e a assume como campo de relação. Ora, isso se manifesta como um desencadear de comportamento. Este é toda relação de abertura, na qual se instaura abertura para algo. Esse algo no pensamento ocidental é denominado de ente: aquilo que está presente. $\mathrm{O}$ ente se propõe na enunciação que a apresenta, de tal modo que a enunciação se submete a ele. É, por um lado, a abertura, mais uma vez, que possibilita o ente ser essa medida diretora da enunciação apresentativa, mas que, por outro lado e ao mesmo tempo, deve deixar-se guiar, previamente, por tal medida.

A abertura como tal é sinônima de liberdade. A conformidade, da verdade no sentido tradicional, só é possível, portanto, na instauração do âmbito de nós mesmos enquanto ser livre. Ocupável ${ }^{3}$. A essência da verdade não pode ser outra, desse modo, senão a liberdade. Contudo, não a liberdade entendida correntemente, mas a liberdade originária ou ek-sistente. A liberdade do único ente que existe: Dasein ${ }^{4}$. Nesse contexto, a liberdade se abre como o deixar-ser o ente, que não significa negativamente omissão ou indiferença em relação ao ente, mas entregar-se ao ente, que, por sua vez, significa entregar-se ao aberto e à sua abertura. Nesta última é que todo ente entra e permanece. O termo alétheia (desvelamento) — anterior a Sócrates — expressa bem esse fenômeno. Daí que, para Heidegger, se, ao invés de usarmos verdade, usarmos alétheia, 
mais nos aproximamos de um pensar originário da essência da verdade. ${ }^{5}$ É assim que, "o deixar-ser, [...] é em si mesmo, a exposição ao ente, isto é, ek-sistente. A essência da liberdade, entrevista à luz da essência da verdade, aparece como ex-posição ao ente enquanto ele tem o caráter de desvelado" (1991a, p.128). Com um jogo de palavras, a essência da liberdade é dita, assim, por Heidegger: desencobrimento, desvelamento, desocultação, abertura e clareira. ${ }^{6}$

A existência, fundada na verdade como liberdade, retém o que lhe é próprio e passa a ser pensada como "[...] ex-posição ao caráter desvelado do ente como tal." (Ibid., p.129). Também a relação do humano com a liberdade retém, nesse contexto, o seu lugar originário. Não é o humano que possui a liberdade, mas a liberdade que o possui, uma vez que somente ela permite a humanidade inaugurar a revelação do ente em sua totalidade ou enquanto tal. Somente aí, enquanto existente possuído pela liberdade ${ }^{7}$, nos lembra STEIN (2002, p.73-88), ao humano é oferecido algo passível de escolha, o ente enquanto possibilidade, e algo não passível de escolha, o ente enquanto necessário.

Heidegger, por essa razão, contrapõe o modo grego de entender a técnica (Téchne) ao moderno (Maquinação). No primeiro, a técnica é um modo de desvelamento do ser. No segundo, o seu mais elevado grau de esquecimento. No mundo moderno, como mostrou Habermas (1994), técnica significa atividade do humano enquanto dominador. A ideia do humano enquanto receptivo, aquele que acolhe e guarda o ser, não é presente no mundo tecnicista atual. É, pois num determinado período da história da filosofia, em que a filosofia enquanto uma metafísica, na qual o humano é tido como subjectum determinante do ser, que não o deixa se manifestar naquilo que é, mas tem como medida do ser o poder de uma razão calculativa, que a técnica, como entendida atualmente, pôde surgir.

O marco histórico fundamental é o século XVII, quando essa filosofia, enquanto metafísica, tornou-se ciência. Descartes, que é expressão, a um só tempo, da ciência moderna nascente e da metafísica que a subjaz, é ponto-chave no entendimento dessa questão. Ele não tematizou o ser por tê-lo, tal como na tradição metafísica, como evidente $^{8}$ e sem realidade ${ }^{9}$, mas conduziu suas análises à base de uma subjacente ideia de ser como permanência ou presença constante (HEIDEGGER, 1989, p. 142 ). ${ }^{10} \mathrm{Com}$ efeito, o iniciador da filosofia moderna, vê, por exemplo, na extensão, a substancialidade da substância corpórea ou o mundo. Isto porque, a extensão é, dentre vários atributos da res corpórea, aquele que, por um lado, permanece invariável em meio as suas possibilidades de variação, e, por outro, faz dos outros seus atributos, tais como: dureza, cor, movimento e etc., apenas seus modos variantes.

Heidegger, nesse contexto, pergunta-se quanto ao modo de ser do Dasein que é estabelecido, por Descartes, como via de acesso a esse mundo enquanto extensão. $\mathrm{O}$ conhecimento matemático é a resposta encontrada. Ele é a via de acesso seguro ao mundo e, mais ainda, esse modo de apreensão do ente assume o caráter de critério de ser; assim:

Em sentido próprio, só é aquilo que tem o modo de ser capaz de satisfazer ao ser acessível no conhecimento matemático. Propriamente só é o que permanece. E é isso que a matemática conhece. O que no ente se torna acessível pela matemática constitui, portanto, o seu ser. (Ibid., p. 142) ${ }^{11}$ 
Heidegger conclui que Descartes, de uma determinada ideia de ser e a partir de seu modo de apreensão, dita ao mundo o seu ser. Ele, assim, não retira o modo de ser dos entes deles mesmos, mas de uma ideia de ser não tematizada. ${ }^{12}$ A razão fundamental, segundo Heidegger, para o predomínio da técnica no mundo ocidental é essa compreensão do sentido do ser não tematizada que o subjaz.

Portanto, a ciência e a técnica, que se pretendem longe de toda metafísica, edificam-se sobre uma compreensão metafísica do sentido de ser. E o determinante último desse sentido é o humano enquanto sujeito. Ele é, nessa perspectiva, o subjectum primeiro e único que faz dos outros entes simples objetos disponíveis a serem construídos e representados. Temos, desse modo, o sentido do ser determinado pelo humano que, fechado em sua atividade técnica, fecha-se para o ser ele mesmo. Para o horizonte esquecido pela metafísica: o da sua finitude. É necessário pensar a técnica no horizonte da finitude ou do pensar do ser: abertura e desvelamento.

\section{TÉCNICA, CIÊNCIA E METAFÍSICA}

Heidegger, em seu texto Die Zeit des Weltbildes $(1938)^{13}$, mostra que a técnica não é mero fenômeno derivado da ciência moderna. Entender a técnica como simples aplicação da ciência é pouco, pois ela, enquanto transformação da prática exige a aplicação da ciência matemática. Nisso a questão é saber qual a concepção do existente e da verdade que fundamenta essa exigência; em outros termos, qual a metafísica que sustenta essa exigência, vez que assim como a partir dos fenômenos, pode-se se chegar à metafísica que lhes fundou, pode-se a partir da metafísica fundante, entender os fenômenos que lhe corresponde. A trilha que Heidegger segue é essa última. Ao percorrer esse caminho ele não quer simplesmente conhecer a essência da técnica moderna, mas conhecê-la para compreender o seu predomínio na modernidade e apontar para a possibilidade de nossa relação livre com isso que é nosso destino.

A essência da ciência moderna é a investigação. Esta significa que o conhecer se instala a si mesmo como processo em um domínio do ente. Processo, por sua vez, não se reduz a método, pois requer um campo aberto no qual se mova. Abrir esse campo é o processo fundamental da investigação. Assim, por exemplo, o esboço de um determinado domínio do existente como a natureza, tem que já trazer o modo como o processo cognoscitivo deve combinar com tal campo aberto. Nisso consiste o rigor da investigação.

A investigação, essência da ciência moderna, está assentada numa determinada concepção do existente e da verdade. Assim é que ela "dispõe do existente se pode contar de antemão com ele em seu transcurso futuro ou a posteriori como passado" (HEIDEGGER, 1962, p.113-4). Somente o que desse modo se converte em objeto se tem por existente. A “[...] ciência como investigação só acontece quando o ser do existente se busca em tal objetividade" (Ibid., p. 114). Essa objetivação se dá num representar que põe ante si o existente em qualquer momento. Assim, o humano calculador pode estar seguro do existente. A verdade se converte, nesse contexto, em certeza do representar e isso torna possível a ciência como investigação.

O decisivo para se compreender a essência da ciência moderna e também da técnica moderna que lhe corresponde é compreender que a essência do humano, ao se 
converter em sujeito, sofreu uma absoluta transformação. Ele é agora, "livre" do mundo antigo e medieval, subjectum: o "[...] existente no qual se funda todo o existente à maneira de seu ser e de sua verdade" (Ibid., p.115). Desse modo, a totalidade do existente começa a ser e, só é, caso seja colocada pelo humano, que "representa e elabora" (Ibid., p.117). O mundo passa a ser compreendido como imagem. Isso é uma característica especifica da Idade Moderna, pois para o medieval o existente é um ente criado por Deus. Ser existente significa: pertencer à ordem do criado. Para o helenismo "o existente é o que nasce e se manifesta, o que como presente acontece ao humano como presente" (Ibid., p.118.). O existente, portanto, não começa a ser pelo fato de que o humano o contemple, no sentido do representar. Ao contrário, o humano é contemplado pelo existente; "o humano grego é ao perceber o existente" (Ibid. p.119). O perceber grego é, portanto, totalmente diferente do representar moderno. Representar moderno significa: "levar ante si o existente como um oposto" (Ibid., p.119): objetivalo. Em uma palavra, o humano se põe enquanto imagem objetivante ${ }^{14}$.

A questão fundamental, porém, que distingue a relação moderna do humano com o existente da antiga e da medieval, é que, na modernidade ele mesmo se põe como estando numa postura nova frente ao existente. E, mais, a tem como "o terreno favorável a um desenvolvimento possível da humanidade" (Ibid.,p.120). Isto é, ela dá inicio ao modo de ser humano enquanto medida e execução para a dominação da totalidade do existente. O Moderno não somente é novo, mas ele se põe como novo.

Essa característica do humano, enquanto medida e execução, tem seu apogeu "[...] no imperialismo planetário do humano tecnicamente organizado" (Ibid., p.144). Abandonar este destino ou quebrá-lo autoritariamente não é possível ao ser humano, mas ele pode meditar ${ }^{15}$ que o ser-sujeito do humano não foi, nem nunca será, a única possibilidade do incipiente ser do humano histórico (Ibid., 144-145). Desse modo, também a técnica, enquanto dominação, não é sua única possibilidade.

Não é sem razão, portanto, que Heidegger procura retornar à compreensão da técnica no pensamento grego como téchne. Lá "[...] onde a presença das coisas não se condicionava às representações da consciência, mas se manifestava por si mesma" (CAMPOS, 1984, p. 54). Onde verdade ainda não era adequação ou conformidade. O que faz a técnica ser uma ameaça não é, então, ela mesma, mas a não apreensão da sua essência, pois "[...] não existe nada de demoníaco na técnica, o que existe é o mistério da sua essência" (HEIDEGGER, 1958, p. 37 apud CAMPOS, 1984, p. 54). Mistério porque o imperialismo da técnica leva a efeito, no mais alto grau, aquilo que, nem a técnica tem controle, mas que tem dominado toda a história do ocidente: a metafísica do esquecimento $^{16}$ do ser. $^{17}$

\section{CONCLUSÃo}

Segundo Heidegger, téchne é, no pensamento grego, entendida antes como saber que um fazer. Saber é um ver-além. Ver-além é determinar, previamente, o subsistente. É, portanto, transcendência. Ao realizar a transcendência o humano instaura a diferença ontológica, isto é, distingue ser do ente. Tal instauração equivale a um modo de desvelamento ou alétheia. Assim Téchne, como alétheia, aproxima-se de poieses. Poiesis é pro-dução, enquanto o mais elevado modo de abertura ao ser dos entes 
(CAMPOS, 1984, p.57s). Isso a põe, em última instância, no âmbito da physis: na “eclosão dos seres" em sua verdade.

Desse modo, pode-se concluir que o aspecto ativo da técnica como téchne nada tem haver com pura dominação e controle, mas com pro-dução do ente. Ou seja, em

164 prol do ente em seu desvelamento. Nessa produção o humano não destrói o seu pacto originário com o mundo, mas o mantém. O humano mantem-se livre no convívio da usina hidroelétrica que está no rio e não o contrário. A tecnificação do pensamento do Ser como o horizonte de determinação do ente na totalidade se mostra aqui como o perigo da técnica. $\mathrm{O}$ que mais nos ameaça na técnica em seu predomínio atual.

Eis o que consideramos o que importa a Heidegger, no horizonte da questão do ser, nos chamar a atenção na questão da técnica. Eis o que consideramos seu legado nessa questão e que não devemos perder de vista.Heidegger não está preocupado com a técnica, mas com o pensamento da técnica.Pensamento, que do ponto de vista originário ou do pensamento que medita, não é da técnica, mas do Ser. A ele devemos sempre retornar, pois ele e somente ele nos põe no livre, e, por isso, no radical pensar do Ser: naquele que nos pode pôr numa relação livre com aquilo que é nosso destino: a técnica. :

\section{REFERÊNCIAS}

CAMPOS, Maria J. Rua Heidegger e a reflexão sobre a técnica. In: Kriterion: revista de filosofia. Belo Horizonte: Resenha 72, Janeiro a Junho, 1984, p.53-63.

CARVALHO, H.B. A de. Hans Jonas e o giro empírico da filosofia da tecnologia: notas sobre um diálogo com a pós-fenomenologia. Filosofia Unisinos - Unisinos Journal of Philosophy. 21(1): 56-71, jan./abr. 2020.

HABERMAS, J. Técnica e ciência como "Ideologia". Trad. Artur Morão. Lisboa: Edições 70, 1994.

HEIDEGGER, Martin. Chemins qui ne mènent nulle part. Éditions Gallimard, 1962 (Col. TEL).

HEIDEGGER, Martin. Introdução à metafísica. Trad. Emannuel Carneiro Leão. Rio de Janeiro: Tempo Brasileiro, 1987, p. 170-176.

HEIDEGGER, Martin. Ser e tempo. 3. ed.Trad. Márcia de Sá Cavalcante. Petrópoles, RJ: Vozes, 1989.

HEIDEGGER, Martin. Sobre a essência da verdade. In. Conferências e escritos filosóficos. 4. ed. Trad. Ernildo Stein. São Paulo: Nova Cultural, 1991a (Os Pensadores).

HEIDEGGER, Martin. O fim da filosofia e a tarefa do pensamento. In: Conferências e escritos filosóficos. 4. ed. Trad. Ernildo Stein. São Paulo: Nova Cultural, 1991b (Os Pensadores).

HEIDEGGER, Martin. A tese de kant sobre o ser. In: Conferências e escritos filosóficos. 4. ed. Trad. Ernildo Stein. São Paulo: Nova Cultural, 1991c (Os Pensadores).

HEIDEGGER, Martin. A questão da técnica. Trad. de Emmanuel Carneiro Leão. In: Ensaios e conferências. Petrópolis, RJ: Vozes, 2002.

HEIDEGGER, Martin. A Origem da obra de arte. Trad. de Maria da Conceição Costa, Lisboa: edições 70, 1992.

HEIDEGGER, Martin. Prolegômenos a história do conceito de tempo. Trad. Jaime Aspiunza Elguezabal. Madrid: Alianza Editorial, 2007.

HEIDEGGER, Martin. Seminario de Le Thor. Trad. Diego Tatián. Córdoba-Argentina: Alción Editora, 1995.

HEIDEGGER, Martin. As questões fundamentais da filosofia ("problemas" seletos de "lógica"). 
Trad. Marco Antonio Casanova. São Paulo: Editora WMF Martins Fontes, 2017.

HEIDEGGER, Martin. Serenidade. Trad. de Maria Madalena Andrade e Olga Santos. Lisboa: Instituto Piaget, 2000.

HEIDEGGER, Martin. Língua técnica e língua de tradição. Tradução de Mario Botas. 2.ed. Lisboa: Passagens, 1999.

HEIDEGGER, Martin. Ciência e meditação. In: Ensaios e conferências. Petrópolis, RJ: Vozes, 2002.

HEIDEGGER, Martin. Seminários de Zollikon. Trad. de Gabriela Arnhold e Maria de Fátima de A. Prado. Petrópolis, RJ: Vozes, 2001.

INWOOD, M. Dicionário Heidegger. Trad. Luísa Buarque de Holanda. Rio de Janeiro: Jorge Zahar Ed., 2002.

NASSER, Eduardo. O tempo em Platão: os meandros da leitura heideggeriana. Revista Hypnos,

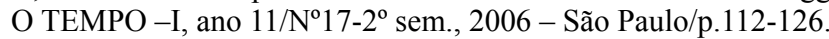

STEIN, Ernildo. Seis estudos sobre "Ser e tempo". 3. ed. Petrópolis, RJ: Vozes, 2005.

\section{Notas}

1 Heidegger resume esse fenômeno do esquecimento do ser no horizonte de uma ambiguidade que há na téchne grega, do seguinte modo: téchne é realização da apreensão da physis em sua alétheia -desvelamento do ente como ente, que tem no taumázein a tonalidade afetiva fundamental, mas é também solo para a sua transformação como homoíosis - correção. No primeiro caso, a téchne apreende a physis sem de ela sair, mas de dentro. No segundo caso, a téchne apreende a physis saindo dela, como algo de fora. Aqui o caminho de abandono do sentido originário da alétheia, com efeito no "início, a questão acerca do ente mantém-se na claridade da alétheia como o caráter fundamental do ente. A própria alétheia, contudo, permanece necessariamente inquestionada. Mas a manutenção de fora da posição inicial, no sentido da téchne, conduz a uma decadência do início. O ente se torna, dito de maneira acentuada, o objeto do re-presentar que se orienta (se retifica) por esse objeto. Agora também se levanta a pergunta acerca da alétheia, mas, desde então, apenas a partir do campo de visão da téchne, e a alétheia transforma-se na correção do representar e do proceder." (2017, p.228-230).

2 Cf. o recente artigo de CARVALHO (2020) que passa em revista a essa área da filosofia atual no tocante a essas duas linhas: a da continuidade, embora com ressalvas, na linha da Filosofia continental ou clássica da tecnologia e a da crítica, na linha de uma desistência do modo de leitura heideggeriana da técnica por julgar que o mesmo teria incorrido numa substantivação da técnica, na linha chamada de Filosofia empírica da técnica.

3 Aqui a referência última é à metáfora da clareira utilizado por Heidegger e explicitada (2001, p.41-2) do seguinte modo em seu sentido mais preciso: "Clareira [Lichtung] não tem nada haver com luz [Licht], mas vem de 'leve' [Leicht]. Luz tem haver com percepção. No escuro ainda se pode esbarar. Isto não necessita de luz, mas de clareira. Luz - claro; clareira vem de leve, tornar livre. Uma clareira no bosque está aí mesmo quando está no escuro. Luz pressupõe clareira. Só pode haver claridade onde foi feita uma clareira, onde está livre para a luz. O escurecer, o tirar a luz não toca a clareira. A clareira é o pressuposto de que pode haver claridade e escuridão, o livre, o aberto. Esse livre ou aberto, Heidegger, chama a atenção, na sequência desse primeiro esclarecimento semântico, é o livre ou aberto para algo, portanto, não o vazio pura e simplesmente que lhe pressupõe, sendo apenas o livre não ocupado, mas o ocupável, inclusive pelo vazio.

4 Temos como escolha didática sempre manter o termo alemão, por considerar que nenhuma das traduções correntes até o momento, como "pre-sença"; "ser-aí"; "estar-aí"; "eis-aí-ser"; "ser-aí humano" nos livram da dificuldade da compreensão inerente ao termo Dasein e por vezes podem até atrapalhar. Se tivéssemos que escolher, como tentativa de facilitar tal compreensão, a tradução por "ser-aí humano", seria a nossa opção.

$5 \mathrm{O}$ estudioso de Platão e do pensamento grego arcaico, Friedlander, afirma que o "a" de alétheia não é nunca negativo no pensamento grego. Isso teria motivado certa mudança de 
Heidegger quanto à busca nos pré-socráticos do testemunho de alétheia tal como ele a pensa como desvelamento, embora ele mantenha sua critica ao predomínio da noção de verdade como justeza do conhecimento a seu objeto. (FRIEDLANDER, 1958 apud NASSER, 2006, nota 24, p.119). Com efeito, Heidegger, vai mudando de pensamento quanto ao modo de tratamento da palavra alétheia dado a ela por ele em relação ao pensamento grego, assumindo que os gregos a experimentaram como desvelamento, mas não chegaram a pensá-la da maneira como ele a pensou na ênfase ao ocultamento, velamento, encobrimento. Ele assim estava meio que sozinho nesse modo de tratamento da verdade (1991b, p.80). Em textos anteriores essa mudança já estava prelineada. Assim, na Origem da obra de arte, embora um texto da década de 30, Heidegger faz uma afirmação que está a meio caminho dessa mudança: "[...] a história oculta da filosofia grega consiste, desde o princípio, no facto de ela não permanecer conforme à essência da verdade que luz na palavra alétheia, e no fato de ela ter de deslocar cada vez mais o seu saber e dizer, da essência da verdade para o apuramento de uma essência derivada de verdade. A essência da verdade como alétheia permanece impensada no pensamento dos gregos e, desde então, e por maioria de razão, na filosofia posterior. A desocultação é para o pensar o que há de mais oculto no ser-aí grego, mas simultaneamente é o que determina, desde cedo, toda a adveniência do advento." (2002, p.40). Também, e de modo mais explícito e decidido, no texto de 1937/38 (2017) essa mudança se mostra presente. Conforme ZAN (1994 apud COSTA, 2002, p.35, nota 24) esse movimento teria se radicalizado em Heidegger a ponto do mesmo reconhecer como um erro conduzir a pergunta pela verdade como a pergunta pela alétheia ou desocultação como tal. Abertura para algo como tal vai ficando sem nome. E, segundo as analises de Tugendheit, cada vez mais distante de uma função crítica da verdade (CORETH, 1973 apud COSTA, 2002, p.36, nota 27).

6 Em HEIDEGGER (1992) temos um dos caminhos empreendidos por ele de mostração da alétheia como o deixar acontecer desocultação como tal em relação ao ente na totalidade. Verdade como adequação do pensamento propositivo à coisa supõe que a coisa já esteja na desocultação. "O enunciado é verdadeiro na medida em que se regula pela desocultação, a saber, pela verdade.” (Ibid., p.41). Aqui circularidade: justeza do enunciado e desocultação. Assim fica claro que "[...] esta essência da verdade, para nós corrente, a justeza da representação (Vorstellen), depende em absoluto da verdade como desocultação."(Ibid., p.41). De sorte que, Heidegger enfatiza que quando "nós aqui e de resto compreendemos a verdade como desocultação, não nos refugiamos apenas numa tradução mais literal de uma palavra grega. Meditamos sobre o que enquanto não experimentado e não pensado subjaz à essência da verdade para nós corrente e por isso gasta, no sentido de justeza" (Ibid., p. 41). "Ora, precisamente não somos nós que pressupomos a desocultação do ente, mas é assim a desocultação do ente (o ser) que nos determina numa essência tal que, na nossa representação, permanecemos inseridos, ficamos sempre a reboque da desocultação." (Ibid., p.41). Em síntese a essência da verdade, ela toda em sentido originário como desocultação, diz: "O ente está no ser" (Ibid., p.42). Desocultação é caráter do ente na totalidade. Importa chamar a atenção aí na essência da verdade como desocultação para um aspecto que aqui não estamos abordando: o ter que ir além da lógica na determinação da verdade. Se digo que o enunciado A se ajusta a coisa B, supõe-se que eu já saiba a coisa. Já tenha tido, de algum modo, a experiência da coisa B. Esse é o pressuposto da ideia de verdade como justeza do enunciado à coisa, mas ficar nesse nível é ficar no nível da lógica. Ainda não é atingir o nível da alétheia heideggeriana, que é o nível da desocultação. Portanto, é preciso libertar a verdade desse nível da lógica para se ter acesso à experiência da desocultação com tal, que permite esse nível da verdade fundada na lógica e qualquer outro comportamento do Dasein e, ainda mais, é preciso manter-se na pergunta sobre a desocultação como tal. Esse último passo faltou, segundo Heidegger, aos gregos, que ficaram somente na experiência da desocultação do ente e não na meditação dessa experiência como experiência do pensamento do ser. Heidegger (2017, p.170-1) nos está conduzindo para o pensamento desse nível da desocultação como tal, quando pensa a essência da verdade. 
Mas, ao contrário, acomodamo-nos "às vezes ao reconhecimento de que, naturalmente para documentar e conceber a justeza (verdade) de uma proposição temos de recorrer a algo que já está manifesto. E que esta suposição é reveladora de algo de incontornável" (1992, p. 41). Segundo Heidegger, porém, enquanto "falarmos e pensarmos assim, compreendemos a verdade sempre e só como justeza, que decerto exige ainda uma condição prévia, que nós próprio fazemos - sabe Deus como e porquê" (Ibid., p. 41). Ou seja, permanecemos acomodados no âmbito da lógica. Não radicalizamos nosso olhar e compreensão para o fato de que não "aquilo a que (wonach) um conhecimento se ajusta, deve já de algum modo estar a descoberto, mas também todo o domínio em que se move este 'ajustar-se [lógico] a qualquer coisa', bem como aquilo para o qual uma adequação do enunciado à coisa se torna manifesta, deve já desenrolar-se totalmente na desocultação" (Ibid., p. 41, grifo meu). Assim, conclui, enfaticamente, nosso filósofo, que nós "e todas nossas representações adequadas não seriam nada e não poderíamos sequer pressupor que estivesse já manifesto algo a que nos ajustássemos, se a desocultação do ente não nos tivesse já exposto nesta clareira, onde todo ente se salienta para nós, e a partir da qual todo ente se retrai" (Ibid., p. 41-42).

7 Outra maneira de dizer isso é afirmar antropologicamente: o humano é dado em liberdade.

8 Heidegger (1989) inicia Ser e tempo discutindo o que ele nomeia de preconceitos acerca do ser na tradição: ele é universal, indefinível e, portanto, evidente.

9 Kant é testemunho moderno desse sentido ditado ao ser: ele não é um atributo real (HEIDEGGER, 1991c).

10 HEIDEGGER (2017) mostra que os quatro sentidos de essência no pensamento grego (METAFÍSICA Livro Z): em geral(comum; universal), proveniência de algo, a priori e de fundamento tem como ponto em comum esse sentido de presença constante que permite o encontro com algo particular e passageiro.

11 Horizonte em que se manteve mesmo Husserl: o da consciência pura absoluta (HEIDEGGER, 2007).

12 Crítica que também valerá, paradoxalmente, para Husserl. Segundo Heidegger (2007) ele não foi, nesse sentido, fenomenológico ou fiel à própria fenomenologia.

13 Aqui, utilizo a edição francesa (1962) e todas as traduções são minha. Considerando o contexto de nossa proposta de trabalho, podemos traduzir Weltbild por "objetivação do mundo", de sorte que o título dessa conferência de Heidegger poderia ser esse: $A$ época da objetivação do mundo.

14 Em 1969 no Seminário de le Thor, Heidegger sintetiza esse fenômeno da objetivação do mundo em questão na seguinte fórmula: "Para os gregos, as coisas aparecem. Para Kant, as coisas me aparecem.’'(1995, p.3. Tradução minha)

$15 \mathrm{Em}$ seu texto Serenidade (2000) Heidegger contrapõe um "pensamento que pensa tecnicamente" a um "pensamento que medita" da mesma forma que em seu texto Língua técnica e língua de tradição (1999), contrapõe uma "linguagem reduzida à informação" a uma "linguagem de sentido"; como também em seu texto As questões fundamentais da filosofia (2017) contrapõe uma "meditação histórica" a uma "consideração historiográfica"; ver também, quanto a essa contraposição, seu texto Ciência e meditação (2002).

16 Em um primeiro momento, Heidegger fala de esquecimento como omissão: a) da diferença ontológica ou troca do ser pelo ente, talvez por conta dessa pertença do humano ao mundo; b) do horizonte de compreensão do ser: o tempo; e, c) da analítica do Dasein em sua historicidade (Zeitlichkeit). Em um segundo momento, Heidegger, aponta para o esquecimento como retraimento do ser, é o ser mesmo que se retrai e nisso se preserva (como a Terra no combate com o Mundo na produção-criação da Obra de Arte); mistério diz, sobretudo, desse retraimento vindo, como essencialização, do próprio ser; o ser no seu próprio, repousando em si mesmo, dá-se retraindo.

17 Quanto ao sentido ser, HEIDEGGER (1987, p. 172ss.) nos diz que, de um lado, nós temos o ente que, em sua simples presença carrega uma força provocante; com efeito, a "[...] presença do ente, em qualquer de suas formas, vai, pois inquietar, angustiar e ameaçar o humano", e, de outro lado, temos o humano, o que há de mais inquietante - to 
deinatation; tal expressão significa que o humano, ao mesmo tempo é: o terrível - deinon - não no sentido vulgar, mas no sentido do vigor predominante que provoca, simultaneamente e de modo igual, o terror do pânico ou verdadeira angustia e o temor concentrado, quieto, que vibra em si mesmo; e desse modo a violência, não no sentido do arbítrio e crueldade, é a essência do vigor predominante. Deinon é, também, assim, o vigoroso, aquele que usa e instaura o vigor da violência; a violência é, portanto, não simplesmente característica do agir, mas uma feição fundamental da existência humana; nela o humano realiza sua humanidade; é o ente na totalidade, que impõe ao humano o vigor imperante que o subjuga; todavia, o humano enquanto instaurador, enquanto deixa imperar esse vigor é também aquele que, enquanto violência, se volta contra tal vigor e imposição. A noção de Téchne está associada a essa noção de violência do ser ele mesmo. 